\title{
The INTENSE project: using observations and models to understand the past, present and future of sub-daily rainfall extremes
}

\author{
Stephen Blenkinsop ${ }^{1}$, Hayley J. Fowler ${ }^{1}$, Renaud Barbero ${ }^{2}$, Steven C. Chan ${ }^{1}$, Selma B. Guerreiro ${ }^{1}$, \\ Elizabeth Kendon $^{3}$, Geert Lenderink ${ }^{4}$, Elizabeth Lewis ${ }^{1}$, Xiao-Feng Li $^{1}$, Seth Westra ${ }^{5}$, Lisa Alexander ${ }^{6}$, \\ Richard P. Allan ${ }^{7}$, Peter Berg ${ }^{8}$, Robert J. H. Dunn ${ }^{3}$, Marie Ekström ${ }^{9}$, Jason P. Evans ${ }^{6}$, Greg Holland ${ }^{10}$, \\ Richard Jones $^{3}$, Erik Kjellström ${ }^{8}$, Albert Klein-Tank ${ }^{4}$, Dennis Lettenmaier ${ }^{11}$, Vimal Mishra ${ }^{12}$, \\ Andreas F. Prein ${ }^{10}$, Justin Sheffield ${ }^{13}$, and Mari R. Tye ${ }^{10}$ \\ ${ }^{1}$ School of Engineering, Newcastle University, Newcastle upon Tyne, UK \\ ${ }^{2}$ National Research Institute of Science \& Technology for Environment \\ $\&$ Agriculture, Aix-en-Provence, France \\ ${ }^{3}$ Met Office Hadley Centre, Exeter, UK \\ ${ }^{4}$ Royal Netherlands Meteorological Institute, De Bilt, the Netherlands \\ ${ }^{5}$ School of Civil, Environmental and Mining Engineering, University of Adelaide, Adelaide, Australia \\ ${ }^{6}$ Climate Change Research Centre, University of New South Wales, Sydney, Australia \\ ${ }^{7}$ Department of Meteorology, University of Reading, Reading, UK \\ ${ }^{8}$ Swedish Meteorological and Hydrological Institute, Norrköping, Sweden \\ ${ }^{9}$ School of Earth and Ocean Sciences, Cardiff University, Cardiff, UK \\ ${ }^{10}$ National Center for Atmospheric Research, Boulder, CO, USA \\ ${ }^{11}$ Department of Geography, UCLA, Los Angeles, USA \\ ${ }^{12}$ Indian Institute of Technology Gandhinagar, Gandhinagar, India \\ ${ }^{13}$ Geography and Environment, University of Southampton, Southampton, UK
}

Correspondence: Stephen Blenkinsop (stephen.blenkinsop@newcastle.ac.uk)

Received: 14 February 2018 - Accepted: 5 June 2018 - Published: 19 June 2018

\begin{abstract}
Historical in situ sub-daily rainfall observations are essential for the understanding of short-duration rainfall extremes but records are typically not readily accessible and data are often subject to errors and inhomogeneities. Furthermore, these events are poorly quantified in projections of future climate change making adaptation to the risk of flash flooding problematic. Consequently, knowledge of the processes contributing to intense, short-duration rainfall is less complete compared with those on daily timescales. The INTENSE project is addressing this global challenge by undertaking a data collection initiative that is coupled with advances in high-resolution climate modelling to better understand key processes and likely future change. The project has so far acquired data from over 23000 rain gauges for its global sub-daily rainfall dataset (GSDR) and has provided evidence of an intensification of hourly extremes over the US. Studies of these observations, combined with model simulations, will continue to advance our understanding of the role of local-scale thermodynamics and large-scale atmospheric circulation in the generation of these events and how these might change in the future.
\end{abstract}




\section{Introduction}

Changes in short-duration, heavy rainfall events are an important fingerprint of anthropogenic climate change (Hegerl et al., 2015) and are crucial to quantify as they are associated with flash flooding which poses a significant threat to lives, infrastructure, and natural ecosystems. Quantified estimates of extreme rainfall intensities at sub-daily timescales (down to a few minutes) and spatial scales of $1-10 \mathrm{~km}^{2}$ are needed for urban drainage design (Arnbjerg-Nielsen et al., 2013) and therefore for adaptation to future climate change. Observations confirm basic physics predicting increased atmospheric moisture with warming, fuelling intensification of heavy rainfall (Trenberth et al., 2003). However, understanding how changes to atmospheric moisture will combine with changes in circulation dynamics in a warming world to strengthen or weaken regional increases in intense rainfall remains a key challenge for climate change research (Pfahl et al., 2017). Achieving this requires the improved availability of high-quality, high-resolution rainfall observations (Westra, et al., 2014; Wilby et al., 2017), advances in climate modelling on convection-permitting scales (Westra et al., 2014; Prein et al., 2015, 2017a) and an improved understanding of atmospheric processes that contribute to intense rainfall (O'Gorman, 2015; Lenderink and Fowler, 2017; Pfahl et al., 2017).

This paper summarises how these challenges are being addressed by the INTENSE (INTElligent use of climate models for adaptatioN to non-Stationary hydrological Extremes) project to provide new knowledge relevant to adapting to hydroclimatic risks under climate change.

\section{The INTENSE project}

INTENSE is the first major international effort to focus on global sub-daily rainfall extremes, enabling substantial advances in quantifying observed historical changes and providing the physical understanding of processes necessary for improved regional prediction of change. The project leads the global research effort within the Global Energy and Water Exchanges (GEWEX) Hydroclimatology Panel CrossCutting project on sub-daily precipitation extremes, addressing the World Climate Research Programme "Grand Challenge" on extremes (Alexander et al., 2016). To develop a more thorough understanding of the relationship between large-scale warming, atmospheric circulation and sub-daily extreme rainfall the project is addressing the research areas set out by Westra et al. (2014) through the following aims:

- To undertake a unique, global-scale data collection effort of sub-daily rainfall data and apply a set of quality control methods to construct a new, high-quality global dataset (Sect. 2.1);
- To use this dataset to quantify the nature of global rainfall extremes across multiple timescales and, where possible, quantify recent change (Sect. 2.2);

- To provide new understanding of the influence of climate model resolution and structure on the simulation of rainfall extremes for different climate regimes (Sect. 2.3);

- To combine models and observations to improve understanding of the drivers of rainfall extremes across multiple timescales, examining the influence of local thermodynamics and large-scale atmospheric circulation modes (Sect. 2.4); and

- To use this knowledge to (i) provide a better understanding of the likely responses to warming of rainfall extremes at different timescales and geographic locations, and (ii) use information from climate models in a more informed way to improve climate change adaptation decision making (Sect. 3).

The project structure, main data requirements and outputs are summarised in Fig. 1. Subsequent sections in this paper provide a brief review of current understanding around these themes, incorporating the contributions made by INTENSE researchers and partners (reflected in the authorship of this paper) to this literature. More details of project outputs, including publications, may be found on the INTENSE website $^{1}$ and a summary is provided in Table 1.

\subsection{Data collection and provision}

In situ precipitation data at sub-daily timescales are needed to quantify the characteristics of extreme events for important research questions including the detection of change and for practical applications such as urban drainage design. They are also valuable for the validation of radar and satellite products (Hegerl et al., 2015) and the outputs from climate models (Prein et al., 2015). However, such data are not as extensive, either in time or space, as those for daily rainfall totals (Westra et al., 2014; Hegerl et al., 2015), are subject to a range of sampling and instrument errors and inhomogeneities (Blenkinsop et al., 2017; Westra, et al., 2014; Wilby et al., 2017) and are less freely available compared with daily data (Hegerl et al., 2015). Consequently, compared with extreme rainfall on timescales of a day or longer, globally, sub-daily events have been little studied.

The INTENSE project is therefore focussing on collecting sub-daily rain gauge records, which provide the most accurate representation of the amount of water reaching the ground at a given location. To date, the global sub-daily rainfall dataset (GSDR) we have compiled comprises data from 23687 gauges (Lewis et al., 2018a), having an average record

\footnotetext{
${ }^{1}$ https://research.ncl.ac.uk/intense/outputs/ (last access: 12 June 2018).
} 


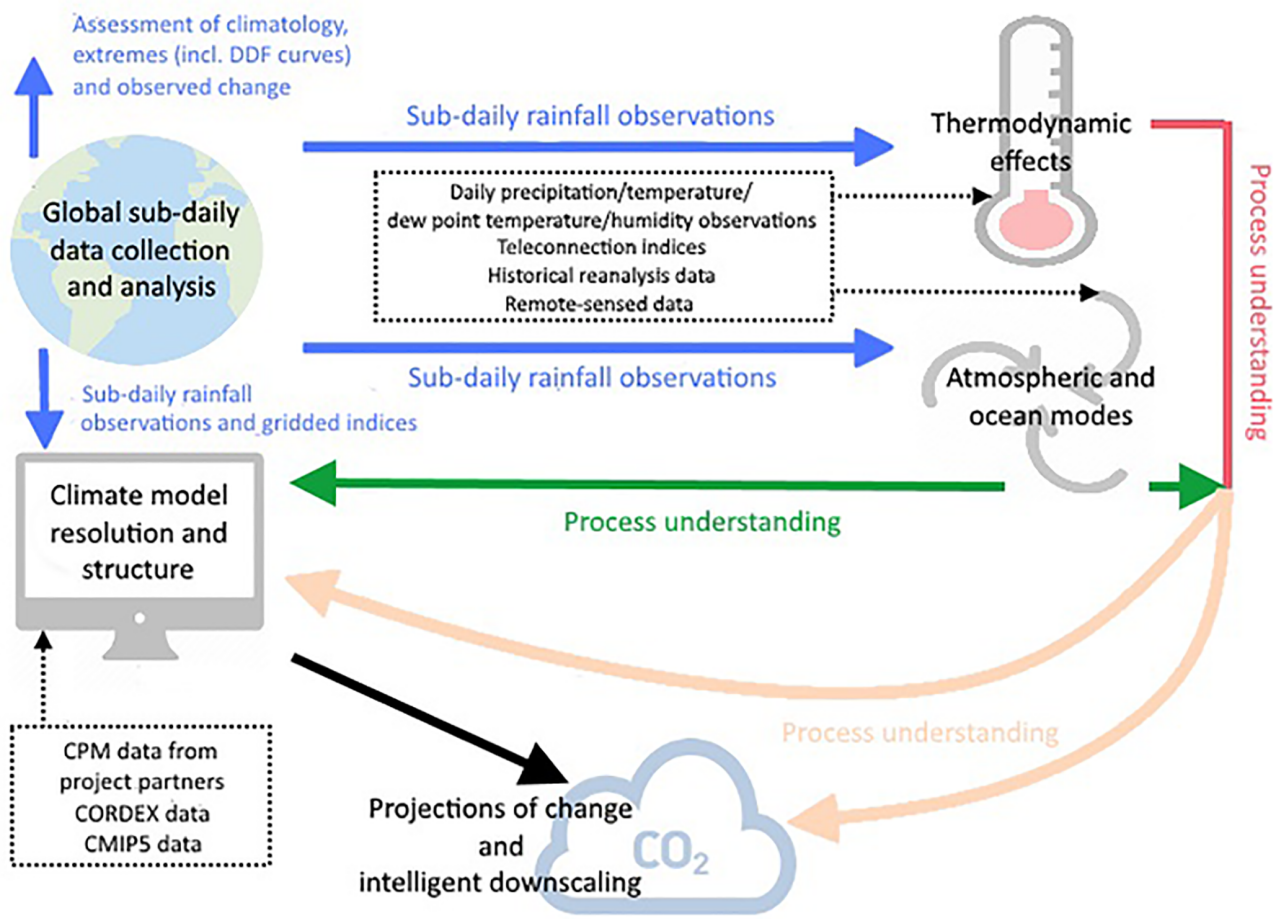

Figure 1. INTENSE project research themes, information flows and outcomes. The collection of in situ sub-daily rain gauge data represents a core project activity (blue arrows). Thermodynamic and atmospheric/ocean processes are considered independently (red and green arrows) but also in an integrated manner (yellow arrows). These data and knowledge will be used to evaluate model simulations of extreme rainfall across different timescales and locations. Model outputs will then be used for the development of process-based downscaling methods and provide guidance on the use of projections (black arrow). Data in dashed boxes denotes externally produced data used in the project.

Table 1. Key outputs from the INTENSE project researchers and partners at time of publication.

\begin{tabular}{ll}
\hline Output & Summary \\
\hline $\begin{array}{l}\text { Global sub-daily rainfall dataset } \\
\text { (GSDR) }\end{array}$ & Hourly rainfall data collected from 23 countries (excluding ISD). \\
\hline $\begin{array}{l}\text { Globally applicable quality control } \\
\text { process }\end{array}$ & $\begin{array}{l}\text { Applied to hourly rainfall accumulations. Will be open-source, and } \\
\text { freely available. }\end{array}$ \\
\hline $\begin{array}{l}\text { Definition of } 13 \text { sub-daily rainfall } \\
\text { indices }\end{array}$ & $\begin{array}{l}\text { Consistent with ETCCDI daily indices but reflecting the intensity, } \\
\text { frequency and time of occurrence of sub-daily extremes. These will } \\
\text { be freely available to the international community and hosted on the } \\
\text { Deutscher Wetterdienst (DWD) GPCC website. }\end{array}$ \\
\hline $\begin{array}{l}15 \text { peer reviewed journal articles } \\
\text { Published research progressing understanding of observed change of } \\
\text { sub-daily extremes, thermo-dynamic and large-scale drivers, and the de- } \\
\text { velopment and analysis of high resolution convection-permitting mod- } \\
\text { els. Includes continental scale analysis of historical US hourly rainfall. }\end{array}$ \\
\hline $\begin{array}{l}\text { Great Britain gridded 1 km hourly } \\
\text { rainfall data (CEH-GEAR1hr) }\end{array}$ & $\begin{array}{l}\text { Hourly } 1 \text { km gridded rainfall dataset based on hourly gauge data and } \\
\text { daily gridded dataset. Will be hosted and periodically updated along- } \\
\text { side the CEH-GEAR dataset by the Centre for Ecology and Hydrology } \\
\text { (CEH) in the UK. }\end{array}$
\end{tabular}




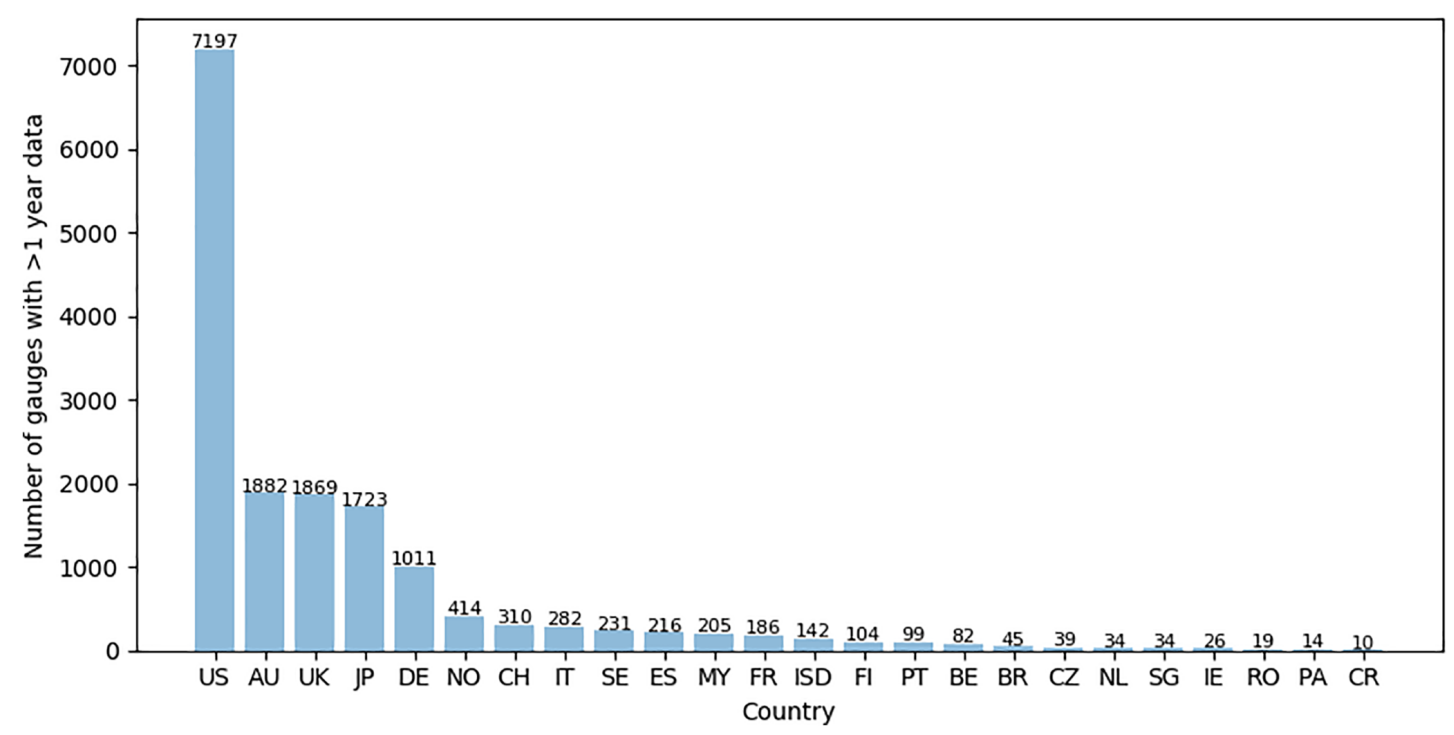

Figure 2. List of countries/data sources contributing at least 10 gauges with a minimum of 1 year of hourly data from the combined data collection exercise and ISD database. Numbers denote the number of gauges. (Abbreviations: US - USA, AU - Australia; UK - United Kingdom, JP - Japan, DE - Germany, NO - Norway, CH - Switzerland, IT - Italy, SE - Sweden, ES - Spain, MY - Malaysia, FR - France, ISD - Non-allocated gauges from the ISD database, FI - Finland, PT - Portugal, BE - Belgium, BR - Brazil, CZ - Czechoslovakia, NL the Netherlands, SG - Singapore, IE - Republic of Ireland, RO - Romania, PA - Panama, CR - Costa Rica.

length of 13 years at an hourly or multi-hourly resolution. Most gauge records commence after 1990 with some continuing up to 2017 although there is a decrease in gauge availability in recent years. Just under half of these are from the Integrated Surface Database (ISD) (Smith et al., 2011), with the remainder being provided by national meteorological and environmental agencies. Figure 2 identifies all those countries contributing at least 10 gauges with a minimum of 1 year of hourly data. Sub-hourly resolution data has also been obtained for the UK and Australia and similar resolution data will be collected for the US to quantify extremes over shorter durations but also to improve estimates of hourly extremes that may be underestimated due to temporal aggregation (Morbidelli et al., 2017).

The collection process revealed that even where data are available they may not be adequate for the analysis of extreme events - for example, undocumented gauge breakdowns, hourly values accumulated as daily totals, or mechanical failure of the rain gauges may produce erroneous rainfall amounts (Blenkinsop et al., 2017). Furthermore, changes such as gauge location, site characteristics or equipment type may introduce inhomogeneities in climatic series (e.g. Barbero et al., 2017). We have therefore developed an automated quality control process for sub-daily data based on methods previously applied to the UK (Blenkinsop et al., 2017; Lewis et al., 2018b) but here used to produce a high-quality global dataset.

Whilst data licensing restrictions mean that the GSDR dataset cannot immediately be made freely available, the data collected will be used to produce a set of sub-daily extreme rainfall indices based on the ETCCDI indices already available for daily data (Peterson, 2005; Donat et al., 2013). These new indices have been identified following discussions with the climate observations and modelling communities and describe important attributes of sub-daily extremes, where possible, corresponding to existing daily ETCCDI indices. For example, indices of monthly maxima of hourly and multihourly rainfall will be provided along with monthly counts of threshold exceedances, as well as indices reflecting the diurnal cycle (e.g. monthly index of the wettest hour). These indices are consistent with the naming and methodological conventions of the ETCCDI daily indices for easy application by users and the data will be made freely accessible for research purposes.

\subsection{Quantifying the nature of extremes and observed change}

Analysis of this global dataset will help quantify the nature of extremes on multiple timescales, expanding regional analyses (e.g. Blenkinsop et al., 2017; Darwish et al., 2018; Forestieri et al., 2018a), and so improve understanding of current patterns of extreme rainfall globally. This will include the spatial pattern of extreme intensities, their seasonality and diurnal cycles. Further, whilst existing studies of long-term trends and variability in sub-daily extremes have tended to cover relatively small spatial domains, INTENSE has already made progress analysing changes at national to continental scales, adding to the national scale studies of Sen Roy (2009) and Westra and Sisson (2011). Whilst US hourly 
and daily seasonal maxima have increased, the percentage of stations showing significant increasing annual maximum precipitation trends was generally higher for daily compared to hourly extremes (Barbero et al., 2017). Strong evidence though points to more widespread increases in the magnitude and frequency of hourly extremes in winter compared to daily extremes. Changes in hourly extremes over the UK are currently difficult to detect as substantial natural climate variability reduces the signal-to-noise ratio (Kendon et al., 2018). Although a recent increase in the intensity of UK summer extremes has been observed, this is likely to be at least partly related to the natural variability of atmospheric and ocean modes.

Our results so far emphasise the importance of considering relevant region-specific atmospheric processes in the assessment of change, and the need to examine sufficiently long time periods and/or large enough datasets. The provision of quality-controlled data means that INTENSE is providing the opportunity to further extend these analyses using the GSDR dataset; approximately $17 \%$ of the gauges obtained so far cover a period of over 30 years necessary for this type of analysis (Lewis et al., 2018a) although this falls to $\sim 4.5 \%$ for periods of over 50 years.

\subsection{Improved modelling capabilities}

Traditional approaches to obtaining projections of regional precipitation change use an ensemble of regional climate models (RCMs) but these typically only provide outputs at a resolution of $10-50 \mathrm{~km}$. Statistical downscaling methods, which include temporal disaggregation approaches, may be used to derive projections of change in sub-daily rainfall but these rely on the assumption that the relationship between rainfall at different timescales (e.g. daily to hourly) remains constant in the future. The INTENSE project has applied this statistical approach to produce projected future depthduration-frequency (DDF) relationships for Sicily, Italy, for rainfall totals down to hourly durations (Forestieri et al., 2018b). However, although state-of-the-art climate models have a high degree of skill in simulating many features of our climate (Flato et al., 2013) they also have a number of known deficiencies. These include the simulation of intense rainfall due to their relatively coarse resolution that cannot explicitly resolve convection which results in the consequent use of convective parameterisation schemes (e.g., Mishra et al., 2012; Mooney et al., 2017). The INTENSE project is linking its observational analyses with the development of very high resolution $(<5 \mathrm{~km})$ convection-permitting models (CPMs) which allow dynamical representation of convection. These have been shown to better simulate sub-daily rainfall characteristics (Kendon et al., 2012; Chan et al., 2014a; Prein et al., 2017b; Lind et al., 2016) including the relationship between temperature and extreme rainfall (Chan et al., 2016a), and produce different projections of change in rainfall intensity, duration and extremes to those from standard coarse resolu- tion models (Kendon et al., 2017). CPMs may also be necessary to provide improved quantification of other hazards including lightning, hail and wind gusts (Kendon et al., 2017; Gadian et al., 2018).

The first study to look at changes in rainfall in long climate change simulations at convection-permitting scale was carried out by the Met Office Hadley Centre (Kendon et al., 2014). These simulations at a resolution of $1.5 \mathrm{~km}$ provided evidence that intense summer rainfall could become heavier over the southern UK with almost five times more events exceeding $28 \mathrm{~mm}$ in one hour (indicative of potential for surface water flooding in the UK) in the future than in the current climate. These simulations have also now been supplemented with corresponding data for the northern half of the UK (Chan et al., 2018a). As part of INTENSE, projected changes in rainfall extremes across timescales in these CPM simulations have been explored alongside observed trends, with implications for detection and attribution studies (Kendon et al., 2018). Data at sub-hourly timescales from these CPMs have also been investigated, with similar changes in summer $10 \mathrm{~min}$ rainfall over the southern UK projected as for hourly timescales (Chan et al., 2016b), but the lack of observed data has precluded model validation to date. The sub-hourly datasets collated in INTENSE will begin to address this deficiency.

CPM climate change simulations are now becoming available across other parts of the globe. For example, using a larger North American domain, Prein et al. (2017c) used a $4 \mathrm{~km}$ resolution CPM to project increases in the maximum rainfall rate in mesoscale convective systems (MCS) in the future. Although some consistent messages are emerging from these studies a better understanding of the differences between models is required, and it is therefore significant that INTENSE is integrating with the main international effort to produce a coordinated set of convection permitting climate simulations through the CORDEX flagship pilot study "Convective phenomena at high resolution over Europe and the Mediterranean"2 . This will maximise the utility of the GSDR dataset and help to integrate knowledge on the key processes and drivers of extreme sub-daily rainfall. This pilot study is focused on Europe, with a number of different groups carrying out $<3 \mathrm{~km}$ resolution climate simulations spanning a common Alpine domain plus, in some cases, additional European sub-domains.

\subsection{Drivers of changes in intense rainfall in a changing climate}

It has been recognised that analyses of observed changes are more powerful if they make use of and diagnose physical mechanisms that are, or may be, responsible for change (Hegerl et al., 2015). INTENSE is therefore investigating the

\footnotetext{
${ }^{2}$ http://www.cordex.org/blog/2018/01/26/endorsed-flagshippilot-studies/ (last access: 8 June 2018).
} 
role of local thermodynamics and large-scale atmosphereocean modes as drivers of changes in intense rainfall through linking observational analyses with those based on CPMs. Observational evidence and climate models suggest that rainfall will intensify with temperature according to the Clausius-Clapeyron (CC) relation (a rate of $\sim 6-7 \%{ }^{\circ} \mathrm{C}^{-1}$ ) (Trenberth et al., 2003; Allen and Ingram, 2002; Allan et al., 2010; Pall et al., 2007) representing an important component of change in the global water cycle (Hegerl et al., 2015). However, larger-scale modes of atmospheric and ocean variability such as the El Niño-Southern Oscillation (ENSO), North Atlantic Oscillation (NAO) and monsoon systems are also important drivers of regional precipitation and extremes, whilst moisture transport features such as atmospheric rivers have been associated with winter flooding in many regions (e.g. Lavers and Villarini, 2013a, b). However, the interaction between these large-scale and thermodynamic processes and their effect on extreme precipitation is not yet well understood.

Our work is using the new observational dataset and modelling capabilities to examine how rainfall extremes respond to increasing temperature and moisture availability globally. Kendon et al. (2018) used a CPM simulation over the southern UK to identify the earlier emergence of future changes in hourly extremes compared with daily extremes which might be expected from enhanced scaling at shorter durations. Such super-CC scaling at hourly timescales has been demonstrated in some regions (e.g. Lenderink and van Meijgaard, 2008) however, CC scaling identified in US daily annual maxima contrasts with lower scaling during most seasons for hourly extremes (Barbero et al., 2017). In the UK, CC scaling is only observed for hourly extremes in summer (Blenkinsop et al., 2015) with lower scaling at other times of the year. To date, most of such studies have examined the rainfall relationship with temperature, but dew point temperature is emerging as a more appropriate variable to use in scaling studies as it provides a direct measure of humidity (Lenderink et al., 2017), enabling a better physical understanding of the scaling relationship (e.g. Lochbihler et al., 2017; Barbero et al., 2018a). INTENSE is taking advantage of global scale observed datasets such as HadISD (Dunn et al., 2016) to perform such analyses more widely.

It is becoming increasingly clear however that future rainfall extremes cannot be simply extrapolated from present day scaling relationships and that multiple other factors - land surface characteristics, temperature range, atmospheric dynamics, large scale circulation and moisture availability - all play key roles (Lenderink and Fowler, 2017; Lochbihler et al., 2017; Prein et al., 2017d; Ali and Mishra, 2017; Bao et al., 2017; Barbero et al., 2018a). Barbero et al. (2018b) found that, apart from in summer, mid-latitude synoptic patterns (including the jet stream and cutoff lows) are major contributors to hourly annual maxima across the western US. Lenderink et al. (2017) also identified the prominent role of circulation features over the Netherlands as measured by the large-scale vertical velocity; the most intense events were typically associated with high vertical velocities which cause a convergence of moist air at a scale of hundreds of kilometers. The use of CPMs is also increasingly offering the potential to contribute to such process understanding; Chan et al. (2018b) used simulations over the southern UK to show that stability, and to a lesser degree relative vorticity and mean sea level pressure, displayed some skill as predictors of hourly extremes. Prein et al. (2017c) showed that the maximum rainfall rate in MCS over North America is increasing in line with $\mathrm{CC}$ but the response in rainfall volume over mesoscale catchments is increasing by up to two times CC rates due to the spread of heavy rainfall areas in future MCS. This is due to changes in the MCS cloud physics and internal dynamics (e.g. vertical mass fluxes).

We think that the key challenge to provide improved projections of future change in sub-daily extremes will be using both the global observation datasets and climate models to understand the contributions from (and interactions between) large-scale circulation and local thermodynamics (Barbero et al., 2018b). As the project progresses, the increasing availability of quality-controlled observations from different climate regimes, particularly in tropical regions, and the increasing modelling capability with mesoscale atmospheric climate models is strengthening our ability to meet this challenge.

\section{Summary and outlook}

The INTENSE project is increasing our understanding of extreme short-duration rainfall events worldwide, linking observations and models to better understand the mechanisms associated with extreme rainfall that can lead to flash flooding. This is partly derived from a data collection initiative that has currently yielded 23687 stations to produce the global sub-daily rainfall dataset (GSDR) which is being used to characterise current extremes and, by linking with the latest CPM simulations, better understand drivers of change. Data collection is ongoing and the project is actively seeking additional contributions to extend coverage (see Lewis et al., 2018a for dataset coverage). We have used the gauge data to produce a $1 \mathrm{~km}$ resolution gridded dataset of historical hourly rainfall for Great Britain which will be freely available to hydrologists, climate modellers and other practitioners (Lewis et al., 2018b). INTENSE will further explore options for combining gauge, radar and satellite data into gridded sub-daily products to add to existing merged products as a key resource for the climate modelling community to validate model outputs (Prein et al., 2015, 2017d). This will help to address problems with the representativeness of rain gauges, as networks are insufficiently dense to capture local-scale convective storms. In the future, model outputs could also be incorporated to provide valuable information in areas with low observational coverage such as mountain- 
ous regions. These INTENSE datasets provide a significant platform for future development by the wider scientific community and efforts are underway to identify a mechanism for their ongoing maintenance and updating to ensure a longterm legacy of the project. The gauge data and new, derived dataset of global sub-daily extreme indices will be hosted by the German meteorological service (Deutscher Wetterdienst - DWD) though the availability of the former will be limited due to licensing arrangements. An improved international capacity to both monitor change and share data therefore remains a significant challenge (Hegerl et al., 2015).

A continental-scale analysis using the sub-daily dataset has not provided evidence of super-CC scaling over the US (Barbero et al., 2017). This may in part be indicative of difficulties associated with capturing changes in localised convective storms (Barbero et al., 2017; Kendon et al., 2018) but also emphasises the need to assess the role of largescale circulation patterns and their relationship with local thermodynamic drivers (Lenderink and Fowler, 2017; Barbero et al., 2018b). This interaction between drivers remains one of the fundamental challenges to be addressed by INTENSE but the global extent of the project also enables it to address, new, emerging questions, for example, ongoing work in the project is examining the contrasting behaviour of extreme rainfall over urban and rural areas, linking observational analyses with simulations from CPMs.

Pioneering work to gain understanding of the benefits of CPMs in representing extreme rainfall on climate timescales by the Met Office Hadley Centre, in collaboration with INTENSE researchers, has led to the inclusion of CPM ensemble simulations (consisting of $10+$ members at $2.2 \mathrm{~km}$ resolution spanning the UK) in the UK's next set of official climate change projections (UKCP, 2016) to be released in 2018. This work at the Met Office Hadley Centre also now includes extensions to examine larger model domains, including the recent completion of a $2.2 \mathrm{~km}$ resolution European domain simulation. Analysis of these simulations in INTENSE, along with comparison of results with those from other international modelling centres across Europe, Australia and the US (e.g. Ban et al., 2015; Argueso et al., 2014; Rasmussen et al., 2014), including CORDEX, will lead to a better understanding of how results from CPMs differ from coarser resolution models more generally (Kendon et al., 2017) to offer robust guidance on their use.

One of the key challenges limiting the application of CPMs is still the computational demand and consequent financial cost they impose. This will in part be addressed by continued advances in computing capabilities but a more intelligent use of these models, aided by novel statistical approaches is necessary for the foreseeable future (Benestad et al., 2017). Chan et al. (2018b) identified large-scale predictors that have some skill in predicting when dynamical downscaling using a CPM is needed. This could potentially allow the targeting of high-resolution models to simulate only periods with a high likelihood of extremes, thus making larger ensembles of CPM simulations more feasible. Even when ensemble large-domain CPM simulations become commonplace, biases will still remain which will require correction with statistical downscaling methods.

A significant area of focus should also include strengthening the link between climate science and impact science (Westra et al., 2014) and the wider impact community. Central to this is the relationship between extreme rainfall and flood risk. Changes in future rainfall intensity can impact on the flooding of urban drainage systems and pollution of coastal waters, for example, in the UK through combined sewer overflow (CSO) spills. Our high-resolution observations and the UK Met Office CPM simulations have been used to demonstrate the need for improved guidance on estimates of change in rainfall intensity (uplifts) for UK water and sewerage companies and the effect of future increases in intensity on increased spills (Dale et al., 2017).

INTENSE outputs could also be used to better understand how river catchments respond to intense rainfall, however, initial work applying uncorrected CPM simulations to the estimation of river flows across catchments in the southern UK indicates greater biases than those from coarser climate models and clear differences in projected flood peaks (Kay et al., 2015). This demonstrates the need for further work investigating the application of new knowledge and tools developed in INTENSE for the assessment of future risks associated with hydrological hazards. INTENSE will provide stakeholders with up-to-date and reliable return period estimates for different rainfall durations (e.g. Forestieri et al., 2018a; Darwish et al., 2018) and so contribute to a better understanding of current flood risk. Combining this type of information with CPM simulations of future projections (e.g. Chan et al., 2014b) will help to make societies more resilient to flooding from intense rainfall.

Data availability. No data sets were used in this article.

Competing interests. The authors declare that they have no conflict of interest.

Special issue statement. This article is part of the special issue "17th EMS Annual Meeting: European Conference for Applied Meteorology and Climatology 2017". It is a result of the EMS Annual Meeting: European Conference for Applied Meteorology and Climatology 2017, Dublin, Ireland, 4-8 September 2017.

Acknowledgements. Hayley J. Fowler leads the European Research Council INTENSE project (ERC-2013-CoG-617329) which has also funded Renaud Barbero, Stephen Blenkinsop, Selma B. Guerreiro, Geert Lenderink, Elizabeth Lewis and Xiao-Feng Li. Hayley J. Fowler is also funded by the Wolfson Foundation and the Royal Society as a Royal Society Wolfson 
Research Merit Award (WM140025) holder. NCAR is sponsored by the National Science Foundation. Richard Allan is funded by the NERC SINATRA project (NE/K00896X/1). Robert J. H. Dunn and Elizabeth Kendon were supported by the Joint UK BEIS/Defra Met Office Hadley Centre Climate Programme (GA01101). The southern UK high-resolution model simulations were funded by the CONVEX project (NERC Changing Water Cycle: NE/I006680/1) and the northern UK simulations were funded by the NUTCAT2050 project (NERC Changing Water Cycle: NE/K002392/1, $\mathrm{NE} / \mathrm{K} 002430 / 1$, NE/K002406/1). The UK $1 \mathrm{~km}$ dataset was part funded by the NERC SINATRA project (NE/K00896X/1). A summary of INTENSE project outputs and activities may be found on the project website: https://research.ncl.ac.uk/intense/aboutintense/ (last access: 12 June 2018). We thank the three anonymous reviewers for their helpful comments and insight.

Edited by: Rasmus Benestad

Reviewed by: three anonymous referees

\section{References}

Alexander, L., Zhang, X., Hegerl, G., Seneviratne, S., Behrangi, A., Fischer, E., Martius, O., Otto, F., Sillmann, J., and Vautard, R.: Implementation plan for WCRP grand challenge on understanding and predicting weather and climate extremes. World Climate Research Programme Report: Geneva, Switzerland, available at: http://www.wcrp-climate.org/gc-extremes-documents (last access: 22 January 2018), 2016.

Ali, H. and Mishra, V.: Contrasting response of rainfall extremes to increase in surface air and dewpoint temperatures at urban locations in India, Sci. Rep., 7, 1228, https://doi.org/10.1038/s41598017-01306-1, 2017.

Allan, R. P., Soden, B. J., John, V. O., Ingram, W., and Good, P.: Current changes in tropical precipitation, Environ. Res. Lett., 5, 025205, https://doi.org/10.1088/1748-9326/5/2/025205, 2010.

Allen, M. R. and Ingram, W. J.: Constraints on future changes in climate and the hydrologic cycle, Nature, 419, 224-232, 2002.

Argueso, D., Evans, J. P., Fita, L., and Bormann, K. J.: Temperature response to future urbanization and climate change, Clim. Dynam., 42, 2183-2199, https://doi.org/10.1007/s00382-013-1789$6,2014$.

Arnbjerg-Nielsen, K., Willems, P., Olsson, J., Beecham, S., Pathirana, A., Bülow Gregersen, I., Madsen, H., and Nguyen, V. T. V.: Impacts of climate change on rainfall extremes and urban drainage systems: a review, Water Sci. Technol., 68, 16-28, 2013.

Ban, N., Schmidli, J., and Schar, C.: Heavy precipitation in a changing climate: Does short-term summer precipitation increase faster?, Geophys. Res. Lett., 42, 1165-1172, https://doi.org/10.1002/2014GL062588, 2015.

Bao, J., Sherwood, S. C., Alexander, L. V., and Evans, J. P.: Future increases in extreme precipitation exceed observed scaling rates, Nat. Clim. Change, 7, 128-132, https://doi.org/10.1038/nclimate3201, 2017.

Barbero, R., Fowler, H. J., Lenderink, G., and Blenkinsop, S.: Is the intensification of precipitation extremes with global warming better detected at hourly than daily resolutions?, Geophys. Res. Lett., 44, 974-983, https://doi.org/10.1002/2016GL071917, 2017.
Barbero, R., Westra, S., Lenderink, G., and Fowler, H. J.: Temperature-extreme precpipitation scaling: a twoway causality?, Int. J. Climatol., 38, e1274-e1279, https://doi.org/10.1002/joc.5370, 2018a.

Barbero, R., Abatzoglou, J. T., and, Fowler, H. J.: Contribution of large-scale midlatitude disturbances to hourly precipitation extremes in the United States, Clim. Dynam., https://doi.org/10.1007/s00382-018-4123-5, online first, 2018b.

Benestad, R., Sillmann, J., Thorarinsdottir, T. L., Guttorp, P., Mesquita, M. d. S., Tye, M. R., Uotila, P., Fox Maule, C., Thejll, P., Drews, M., and Parding, K. M.: New vigour involving statisticians to overcome ensemble fatigue, Nat. Clim. Change, 7, 697703, 2017.

Blenkinsop, S., Chan, S. C., Kendon, E. J., Roberts, N. M., and Fowler, H. J.: Temperature influences on intense UK hourly precipitation and dependency on largescale circulation, Environ. Res. Lett., 10, 054021, https://doi.org/10.1088/17489326/10/5/054021, 2015.

Blenkinsop, S., Lewis, E., Chan, S. C., and Fowler, H. J.: An hourly precipitation dataset and climatology of extremes for the UK, Int. J. Climatol., 37, 722-740, https://doi.org/10.1002/joc.4735, 2017.

Chan, S. C., Kendon, E. J., Fowler, H. J., Blenkinsop, S., Roberts, N., and Ferro, C. A. T.: The value of high-resolution Met Office Hadley Centre regional climate models in the simulation of multi-hourly precipitation extremes, J. Climate, 27, 6155-6174, 2014a.

Chan, S. C., Kendon, E. J., Fowler, H. J., Blenkinsop, S., and Roberts, N. M.: Projected increases in summer and winter UK sub-daily precipitation extremes from high-resolution regional climate models, Environ. Res. Lett., 9, 084019, https://doi.org/10.1088/1748-9326/9/8/084019, 2014b.

Chan, S. C., Kendon, E. J., Roberts, N. M., Fowler, H. J., and Blenkinsop, S.: Downturn in scaling of UK extreme rainfall with temperature for future hottest days, Nat. Geosci., 9, 24-28, https://doi.org/10.1038/ngeo2596, 2016a.

Chan, S. C., Kendon, E. J., Roberts, N. M., Fowler, H. J., and Blenkinsop, S.: The characteristics of summer sub-hourly rainfall over the southern UK in a high-resolution convective permitting model, Environ. Res. Lett., 11, 094024, https://doi.org/10.1088/1748-9326/11/9/094024, 2016b.

Chan, S. C., Kahana, R., Kendon, E. J., and Fowler, H. J.: Projected changes in extreme precipitation over Scotland and Northern England using a high-resolution regional climate model, Clim. Dynam., https://doi.org/10.1007/s00382-018-4096-4, online first, 2018a.

Chan, S. C., Kendon, E. J., Roberts, N., Blenkinsop, S., and Fowler, H. J.: Large-scale predictors for extreme hourly precipitation events in convection-permitting climate simulations, J. Climate, 31, 2115-2131, https://doi.org/10.1175/JCLI-D-170404.1, 2018b.

Dale, M., Luck, B., Fowler, H. J., Blenkinsop, S., Gill, E., Bennett, J., Kendon, E. J., and Chan, S.: New climate change rainfall estimates for sustainable drainage, Engineering Sustainability, 170, 214-224, https://doi.org/10.1680/jensu.15.00030, 2017.

Darwish, M., Fowler, H. J., Blenkinsop, S., and Tye, M. R.: A regional frequency analysis of UK hourly and multi-hourly extreme precipitation, Int. J. Climatol., https://doi.org/10.1002/joc.5694, accepted, 2018. 
Donat, M. G., Alexander, L. V., Yang, H., Durre, I., Vose, R., Dunn, R. J. H., Willett, K. M., Aguilar, E., Brunet, M., Caesar, J., Hewitson, B., Jack, C., Klein Tank, A. M. G., Kruger, A. C., Marengo, J., Peterson, T. C., Renom, M., Oria Rojas, C., Rusticucci, M., Salinger, J., Elrayah, A. S., Sekele, S. S., Srivastava, A. K., Trewin, B., Villarroel, C., Vincent, L. A., Zhai, P., Zhang, X., and Kitching, S.: Updated analyses of temperature and precipitation extreme indices since the beginning of the twentieth century: The HadEX2 dataset, J. Geophys. Res.-Atmos., 118, 2098-2118, https://doi.org/10.1002/jgrd.50150, 2013.

Dunn, R. J. H., Willett, K. M., Parker, D. E., and Mitchell, L.: Expanding HadISD: quality-controlled, sub-daily station data from 1931, Geosci. Instrum. Method. Data Syst., 5, 473-491, https://doi.org/10.5194/gi-5-473-2016, 2016.

Flato, G., Marotzke, J., Abiodun, B., Braconnot, P., Chou, S.C., Collins, W., Cox, P., Driouech, F., Emori, S., Eyring, V., Forest, C., Gleckler, P., Guilyardi, E., Jakob, C., Kattsov, V., Reason, C., and Rummukainen, M.: Evaluation of Climate Models, in: Climate Change 2013: The Physical Science Basis. Contribution of Working Group I to the Fifth Assessment Report of the Intergovernmental Panel on Climate Change, edited by: Stocker, T. F., Qin, D., Plattner, G.-K., Tignor, M., Allen, S. K., Boschung, J., Nauels, A., Xia, Y., Bex, V., and Midgley, P. M., Cambridge University Press, Cambridge, UK and New York, NY, USA, 2013.

Forestieri, A., Lo Conti, F., Blenkinsop, S., Cannarozzo, M., Fowler, H. J., and Noto, L.: Regional frequency analysis of extreme precipitation for Sicily (Italy), Int. J. Climatol., 38, e698-e716, https://doi.org/10.1002/joc.5400, 2018a.

Forestieri, A., Arnone, E., Blenkinsop, S., Candela, A., Fowler, H., and Noto, L. V.: The impact of climate change on extreme precipitation in Sicily, Italy, Hydrol. Process., 32, 332348, https://doi.org/10.1002/hyp.11421, 2018 b.

Gadian, A., Blyth, A., Bruyere, C. L., Burton, R., Done, J., Groves, J., Holland, G., Mobbs, S., Pozo, J. T., Tye, M., and Warner, J.: A case study of possible future summer convective precipitation over the UK and Europe from a regional climate projection, Int. J. Climatol, 38, 2314-2324, https://doi.org/10.1002/joc.5336, 2018.

Hegerl, G. C., Black, E., Allan, R. P., Ingram, W. J., Polson, D., Trenberth, K. E., Chadwick, R. S., Arkin, P. A., Sarojini, B. B., Becker, A., Dai, A., Durack, P. J., Easterling, D., Fowler, H. J., Kendon, E. J., Huffman, G. J., Liu, C., Marsh, R., New, M., Osborn, T. J., Skliris, N., Stott, P. A., Vidale, P. L., Wijffels, S. E., Wilcox, L. J., Willett, K. M., and Zhang, X.: Challenges in Quantifying Changes in the Global Water Cycle, B. Am. Meteorol. Soc., 96, 1097-1115, https://doi.org/10.1175/BAMS-D-13$00212.1,2015$.

Kay, A. L., Rudd, A. C., Davies, H. N., Kendon, E. J., and Jones, R. G.: Use of very high resolution climate model data for hydrological modelling: baseline performance and future flood changes, Climatic Change, 133, 193-208, https://doi.org/10.1007/s10584015-1455-6, 2015.

Kendon, E. J., Roberts, N. M., Senior, C. A., and Roberts, M. J.: Realism of rainfall in a very high resolution regional climate model, J. Climate, 25, 5791-5806, 2012.

Kendon, E. J., Roberts, N. M., Fowler, H. J., Roberts, M. J., Chan, S. C., and Senior, C. A.: Heavier summer downpours with climate change revealed by weather forecast resolution model, Nature Clim. Change, 4, 570-576, 2014.
Kendon, E. J., Ban, N., Roberts, N. M., Fowler, H. J., Roberts, M. J., Chan, S. C., Evans, J. P., Fosser, G., and Wilkinson, J. M.: Do convection-permitting regional climate models improve projections of future precipitation change?, B. Am. Meterol. Soc., 98, 79-93, https://doi.org/10.1175/BAMS-D-15-0004.1, 2017.

Kendon, E. J., Blenkinsop, S., and Fowler, H. J.: When Will We Detect Changes in Short-Duration Precipitation Extremes?, J. Climate, 31, 2945-2964, https://doi.org/10.1175/JCLI-D-170435.1, 2018.

Lavers, D. A. and Villarini, G.: The nexus between atmospheric rivers and extreme precipitation across Europe, Geophys. Res. Lett., 40, 3259-3264, https://doi.org/10.1002/grl.50636, 2013a.

Lavers, D. A. and Villarini, G.: Atmospheric Rivers and Flooding over the Central United States, J. Climate, 6, 829-7836, https://doi.org/10.1175/JCLI-D-13-00212.1, 2013b.

Lenderink, G. and Fowler, H. J.: Understanding precipitation extremes, Nat. Clim. Change, 7, 391-393, https://doi.org/10.1038/nclimate3305, 2017.

Lenderink, G. and van Meijgaard, E.: Increase in hourly precipitation extremes beyond expectations from temperature changes, Nat. Geosci., 1, 511-514, 2008.

Lenderink, G., Barbero, R., Loriaux, J. M., and Fowler, H. J.: SuperClausius-Clapeyron scaling of extreme hourly convective precipitation and its relation to large-scale atmospheric conditions, J. Climate, 30, 6037-6052, https://doi.org/10.1175/JCLI-D-160808.1, 2017.

Lewis, E., Fowler, H. J., Alexander, L., Dunn, R., McClean, F., Barbero, R., Guerreiro, S. B., Li, X.-F., and Blenkinsop, S.: GSDR: A Global sub-daily rainfall dataset, J. Climate, submitted, 2018a.

Lewis, E., Quinn, N., Blenkinsop, S., Fowler, H. J., Freer, J., Tanguy, M., Hitt, O., Coxon, G., Bates, P., and Woods, R.: A rule based quality control method for hourly rainfall data and a $1 \mathrm{~km}$ resolution gridded hourly rainfall dataset for Great Britain: CEHGEAR1hr, J. Hydrol., in revision, 2018 b.

Lind, P., Lindstedt, D., Kjellström, E., and Jones, C.: Spatial and Temporal Characteristics of Summer Precipitation over Central Europe in a Suite of High- Resolution Climate Models, J. Climate, 29, 3501-3518, https://doi.org/10.1175/JCLI-D-150463.1, 2016.

Lochbihler, K., Lenderink, G., and Siebesma, A. P.: The spatial extent of rainfall events and its relation to precipitation scaling, Geophys. Res. Lett., 44, 8629-8636, https://doi.org/10.1002/2017GL074857, 2017.

Mishra, V., Dominguez, F., and Lettenmaier, D. P.: Urban precipitation extremes: How reliable are regional climate models?, Geophys. Res. Lett., 39, L03407, https://doi.org/10.1029/2011GL050658, 2012.

Mooney, P. A., Broderick, C., Bruyère, C. L., Mulligan, F. J., and Prein, A. F.: Clustering of Observed Diurnal Cycles of Precipitation over the United States for Evaluation of a WRF Multiphysics Regional Climate Ensemble, J. Climate, 30, 9267-9286, 2017.

Morbidelli, R., Saltalippi, C., Flammini, A., Cifrodelli, M., Picciafuoco, T., Corradini, C., Casas-Castillo, C. M., Fowler, H. J., and Wilkinson, S. M.: Effect of temporal aggregation on the estimate of annual maximum rainfall depths for the design of hydraulic infrastructure systems, J. Hydrol., 554, 710-720, https://doi.org/10.1016/j.jhydrol.2017.09.050, 2017.

O'Gorman, P. A.: Precipitation extremes under climate change, Current Climate Change Reports, 1, 49-59, 2015. 
Pall, P., Allen, M. R., and Stone, D. A.: Testing the ClausiusClapeyron constraint on changes in extreme precipitation under $\mathrm{CO}_{2}$ warming, Clim. Dynam., 28, 351-363, 2007.

Peterson, T. C.: Climate Change Indices, WMO Bulletin, 54, 83-86, 2005.

Pfahl, S., O'Gorman, P. A., and Fischer, E. M.: Understanding the regional pattern of projected future changes in extreme precipitation, Nat. Clim. Change, 7, 423-427, 2017.

Prein, A. F., Langhans, W., Fosser, G., Ferrone, A., Ban, N., Goergen, K., Keller, M., Tölle, M., Gutjahr, O., Feser, F., Brisson, E., Kollet, S., Schmidli, J., van Lipzig, N. P. M., and Leung, R.: A review on regional convection-permitting climate modeling: Demonstrations, prospects, and challenges, Rev. Geophys., 53, 323-361, 2015.

Prein, A. F., Rasmussen, R., and Stephens, G.: Challenges and advances in convection-permitting climate modeling, B. Am. Meteorol. Soc., 98, 1027-1030, 2017a.

Prein, A. F., Liu, C., Ikeda, K., Bullock, R., Rasmussen, R. M., Holland, G. J., and Clark, M.: Simulating North American mesoscale convective systems with a convection-permitting climate model, Clim. Dynam., https://doi.org/10.1007/s00382-017-3993-2, online first, 2017b.

Prein, A. F., Liu, C., Ikeda, K., Trier, S. B., Rasmussen, R. M., Holland, G. J., and Clark, M. P.: Increased rainfall volume from future convective storms in the US, Nat. Clim. Change, 7, 880-884, 2017c.

Prein, A. F., Rasmussen, R. M., Ikeda, K., Liu, C., Clark, M. P., and Holland, G. J.: The future intensification of hourly precipitation extremes, Nat. Clim. Change, 7, 48-52, 2017d.

Rasmussen, R., Ikeda, K., Liu, C., Gochis, D., Clark, M., Dai, A., Gutmann, E., Dudhia, J., Chen, F., Barlage, M., Yates, D., and Zhang, G.: Climate change impacts on the water balance of the Colorado headwaters: High-resolution regional climate model simulations, J. Hydrometeor., 15, 1091-1116, https://doi.org/10.1175/JHM-D-13-0118.1, 2014.
Sen Roy, S.: A spatial analysis of extreme hourly precipitation patterns in India, Int. J. Climatol., 29, 345-355, https://doi.org/10.1002/joc.1763, 2009.

Smith, A., Lott, N., and Vose, R.: The integrated surface database: recent developments and partnerships, B. Am. Meteorol. Soc., 92, 704-708, 2011.

Trenberth, K. E., Dai, A., Rasmussen, R. M., and Parsons, D. B.: The changing character of precipitation, B. Am. Meteorol. Soc., 84, 1205-1218, 2003.

UKCP: Technical approach to the delivery of new UK Climate Projections (UKCP18 project), UK Climate Projections, available at: http://ukclimateprojections.metoffice.gov.uk/media.jsp? mediaid $=88729 \&$ filetype $=$ pdf (last access: 23 January 2018), 2016.

Westra, S. and Sisson, S. A.: Detection of non-stationarity in precipitation extremes using a max-stable process model, J. Hydrol., 406, 119-128, https://doi.org/10.1016/j.jhydrol.2011.06.014, 2011.

Westra, S., Fowler, H. J., Evans, J. P., Alexander, L. V., Berg, P., Johnson, F., Kendon, E. J., Lenderink, G., and Roberts, N. M.: Future changes to the intensity and frequency of short-duration extreme rainfall, Rev. Geophys., 52, 522-555, https://doi.org/10.1002/2014RG000464, 2014.

Wilby, R. L., Clifford, N. J., De Luca, P., Harrigan, S., Hillier, J. K., Hodgkins, R., Johnson, M. F., Matthews, T. K. R., Murphy, C., Noone, S. J., Parry, S., Prudhomme, C., Rice, S. P., Slater, L. J., Smith, K. A., and Wood, P. J.: The "dirty dozen" of freshwater science: detecting then reconciling hydrological data biases and errors, WIREs Water, 4, e1209, https://doi.org/10.1002/wat2.1209, 2017. 